\title{
The Role of Prosody in Text Interpretation
}

\author{
Mariam Khazhakyan \\ Yerevan State University
}

\begin{abstract}
In this paper, an attempt has been made to show the indispensable role of prosody in the language of drama. Prosody as a reliable means of identifying the meaning in belles-lettres style (drama) is important not only in terms of articulation but also perception and cognition as speech is a bilateral process. As compared with other substyles of the belles-lettres style, the dialogue in drama occupies a leading place. The author's remarks contribute to the correct choice of prosody enabling us to reveal the author's intent. Though represented in the form of dialogues, the language of drama is in no way the exact reproduction of the norms of colloquial language. The playwright will reproduce actual conversation only as far as the norms of the written language will allow. Thus, the language of drama is marked by stylization of colloquial speech preserving the modus of literary language.
\end{abstract}

Key words: belles-lettres style, drama, prosody, prosodic features, sentence prosody, interpretation.

\section{Introduction}

The term prosody is treated differently by different linguists. To avoid a fragmentary study, any confusion and misunderstanding, we have chosen the one that is termed sentence prosody. It groups together intonation, phrasal rhythmic patterning and more general features of prosodic phrasing (Crystal 2008:393) and best suits our purport.

Prosody is a means for "reading with expression" (Erekson 2010:80). Prosody is utilized to basically determine the meaning. It is the music of language. Prosodic features (stress, pitch movement, intonation, pauses, loudness, tempo, 
paralinguistic features, vocal effects) contribute to the meaning of speech. They are used to reveal the extremely rich and varied fluctuations of speech.

\section{Prosody of Drama}

"The Importance of Being Earnest" by Oscar Wilde is a real comedy in the classical sense. It is one of the best examples where all the prosodic features are condensed in such a way, that they best reveal the author's intention. The humour of the play is largely achieved by the juxtaposition of high-flown and prosodic language.

JACK. 'Charming \day it has, been, Miss Fairfax.

GWENDOLEN. Pray 'don't 'talk to me about the, weather, $M r$. ,Worthing. Whenever people 'talk to me a'bout the $\vee$ weather, I always feel $\uparrow$ quite , certain that they 'mean something alse. And , that, makes me $\uparrow$ so, nervous.

JACK. I, do mean some, thing, else.

GWENDOLEN. I, thought, so. In $\rightarrow$ fact, I am $\wedge$ never $\wedge$ wrong.

JACK. And I would 'like to be al'lowed to take ad \vantage of $\downarrow$ Lady $\downarrow$ Bracknell's \temporary $\vee$ absence...

GWENDOLEN. I would \certainly ad \vise you to 'do so. $\vee$ Mamma has a, way of 'coming, back ^suddenly into a , room | that I have $\uparrow$ often had to 'speak to her a, bout.

It is not difficult to notice that there are virtually no pauses in the given passage. This may be explained by the fact that the communicative process takes place on a stage and the actors performing the play know the text perfectly well.

The Falling-Rising $(\vee)$, the Rising-Falling $(\wedge)$, the Level $(\rightarrow)$ tones, the Gradually Descending Stepping Scale, the Broken Descending Stepping Scale and the Sliding Scale are used. The noun weather which represents the neutral layer of the vocabulary acquires a special implication when pronounced with the falling-rising intonation. The speaker hesitates to make the statement too 
confidently and expects the addressee to guess the extra meaning. But this uncertainty makes Gwendolen nervous which is reinforced by the use of the Gradually Descending Stepping Scale. The adverbs quite and so are being pitched higher than the preceding stressed syllables, making the communicative centre of the utterance, thus emphasizing Gwendolen's state of nervousness. The fact that Jack is really concealing something from her, and Gwendolen is aware of the fact, makes her more confident, telling that she can never be wrong. And this daring tone is achieved by the use of the Rising-Falling tone: In $\rightarrow$ fact, I am $\wedge$ never $\wedge$ wrong. She wants to prove her infallibility once again conveying an ironical attitude. The word fact is uttered with a mid-level tone which signifies non-finality. It gives the utterance somewhat uncertainty, but under those circumstances, even the monotonousness of that tone attaches some depth to Gwendolen's speech making it too self-confident. "Style is the physiognomy of the mind, and a safer index to character than the face" (Schopenhauer 2016:1). Thus, it is sometimes more important how you say things than what you say because the tone of the voice, the vocal effects, paralinguistic features, etc. give us more information than the words can suggest. Thus, the phonopragmatic factor acquires special importance as the situation is the best indicator of how to express oneself. But after a moment's seeming hesitation Gwendolen intensifies the fact that she can never be mistaken as if she were speaking about some universal truth which can never fall under suspicion. Jack intends to take the opportunity and make a proposal to Gwendolen, he wants by no means to miss his chance. And the use of the Sliding Scale, in which all the stressed words are equally prominent, is the best choice in this situation: And I would 'like to be al'lowed to take ad \vantage of $\downarrow$ Lady $\downarrow$ Bracknell's ১temporary $\vee$ absence.... Here the word absence is pronounced with the falling-rising intonation. That means that Lady Bracknell may appear anytime, and Jack has no time to be lost. Her absence is temporary and she is present even when she is actually absent. Besides, Gwendolen also wishes the same and does her best for Jack (Ernest, as she thinks) to feel at ease: I would \certainly ad $\downarrow$ vise you to 'do so. $\vee$ Mamma has a, way of'coming, back $\wedge$ suddenly into a ,room | that I have $\uparrow$ often had to `speak to her a bout. 
Gwendolen pushes Jack to an immediate action. She pronounces the adverb suddenly with the rising-falling intonation, thus expressing her disapproval, negative attitude towards her mother's unexpected appearance, and guessing Jack's intention, reinforces the humorous effect of the situation which is revealed by the correct choice of prosodic features, namely - the melody of speech, loudness of voice, as well as paralinguistic and extralinguistic features, such as smile, facial expression, shining eyes.

The passage under discussion is not distinguished by the varied use of connotative words, grammatical, semantic constructions, with the exception perhaps of alliteration expressed by the sound $[s]$, but it is evident that through prosody the addressee is able to fully transmit the information conditioned by situation.

The following passage from the same drama shows how it becomes possible to interpret the speech of the characters and reveal the underlying meanings through prosody.

JACK. [nervously] Miss $\rightarrow$ Fairfax, 'ever since $I$, met $\rightarrow$ you । I have ad'mired you 'more than $\uparrow$ any, girl... I have 'ever, met 'since... I met ,you.

GWENDOLEN. Yes, I am 'quite a ware of the, fact. And I 'often, wish ? that in 'public, । at any $\rightarrow$ rate, ᄂ you had been $\uparrow$ more de'monstrative. For $\rightarrow$ me you have 'always had an $\uparrow$ irre`sistible fasci,nation. ^Even be Ifore I Imet 'you , I was Ifar from in $\nearrow$ different, to you. [Jack looks at her in amazement.] We, live, । as I'hope you, know, Mr. Worthing, 2 in an 'age of i,deals. The 'fact is 'constantly, mentioned in the more ex $\downarrow$ pensive \monthly maga zines, and has 'reached the pro $\wedge$ vincial $\wedge$ pulpits I am , told: and my $\mathrm{i}$ deal, has 'always $\vee$ been l to 'love 'some one of the 'name of .Ernest. There, is 'something in that $\vee$ name l that in'spires $\uparrow$ absolute, confidence. The 'moment, Algernon । first $\checkmark$ mentioned to me 1 that he 'had a Ifriend 'called, Ernest, I 'knew I was 'destined to, love you. 
JACK. You 'really 'love me, , Gwendolen?

GWENDOLEN. |Passionately!

JACK. 'Darling! You 'don't 'know how 'happy you've, made me.

GWENDOLEN. My 'own, Ernest!

JACK. But you ১don't ১really ১mean to, say । that you 'couldn't love me if my \name \wasn't $\wedge$ Ernest?

GWENDOLEN. But your 'name $\uparrow$ is $\wedge$ Ernest.

JACK. 'Yes, I 'know it , is. But sup'posing it was 'something else? $\nearrow$ Do you $\nearrow$ mean to say you 'couldn't $\wedge$ love me then?

GWENDOLEN. [glibly] |Ah! That is 'clearly a 'meta'physical 'specu, lation, । and like $\uparrow$ most meta'physical 'specu, lations has $\downarrow$ very 'little reference at 'all 2 to the 'actual 'facts of 'real, life, I as we, know them.

JACK. 'Personally, ,darling, I to 'speak $\uparrow$ quite , candidly, । I 'don't 'much, care l about the 'name of $\vee$ Ernest... I 'don't $\vee$ think the 'name 'suits me at |all.

$G W E N D O L E N$. It 'suits you per $\wedge$ fectly. It is a di^ vine name. It has a $\wedge$ music of its, own. It produces vi^ brations.

Once you hear the first sounds of the play, it becomes evident that through prosody it is quite possible to identify the emotional state of the characters, their admiration and attitude towards each other and the surrounding world, even their class distinction, making it possible for the addressee to grasp all the shades of meaning in their speech. Gwendolen's speech is stylized, it is marked, whereas Jack's speech is neutral, unmarked. Jack's admiration for Gwendolen is expressed by the gradually descending stepping scale, and fear, anxiety, uncertainty - by the frequent use of pauses, level tones. If compared with Jack's speech, that of Gwendolen is overly self-confident, almost without pauses. The repetition of short vowels, sudden changes of tunes, voice quality, etc. make the speech of the characters more dynamic and funny, thus stimulating the imagination of the addressees and helping them reveal the author's intention. Gwendolen is a smart, purposeful, active, energetic, practical woman, she 
pursues her goal and is always the first to take the initiative. She is eager to get married to someone named Ernest as she thinks it is the only name that is endowed with only positive connotations:

It is a di^ vine name. It has a $\wedge$ music of its, own. It produces vi^ brations.

Throughout the whole play, Oscar Wilde utilizes wit and satire to achieve a humorous effect. Gwendolen creates ideal conditions for Jack to make a marriage proposal to her (she is convinced that Jack's name is Ernest). It's a wonderful occasion for Jack, as he is not indifferent to the young, beautiful, attractive lady, but he tries to indirectly make Gwendolen understand that he is indifferent towards the name Ernest and thinks that the name doesn't suit him at all and there are much better names than that: $\rightarrow$ Well, 'really, Gwendolen, $I$ 'must $\rightarrow$ say that I, think there are 'lots of, other $\uparrow$ much $\wedge$ nicer , names. I think Jack, for $\rightarrow$ instance, a ‘charming, name. Now let us see how Gwendolen interprets Jack's words who is the best source of creating a humorous effect:

GWENDOLEN. 'Jack? ... , No, there is very 'little 'music in the 'name Jack, I if any at all, in, deed. It does not 'thrill. It pro'duces $\uparrow$ absolutely 'no vi,brations.... I have 'known 'several Jacks, I and they, all, without ex'ception, were more than 'usually ,plain. Be $\rightarrow$ sides, 'Jack is a no'torious domes, ticity for $\wedge$ John! And

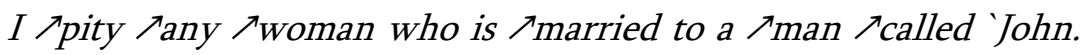
She would 'probably $\uparrow$ never be al' lowed to 'know the en 'trancing ,pleasure of a 'single 'moment's, solitude. The „only really ‘safe , name is Ernest.

We may deduce from the above-given example that there is condensed humor, and even irony in Gwendolen's words. The irony is addressed to all those who are not called Ernest. This is an issue of principle for her. The irony in her speech is manifested through melody which is achieved by the use of the sliding scale, 
different facial gestures, changes in voice quality, stylized speech. A man's style, as A. Schopenhauer formulates, shows the formal nature of all his thoughts - the formal nature which can never change, be the subject or the character of his thoughts what it may: it is, as it were, the dough out of which all the contents of his mind are kneaded. And the prosody seems to make this idea full and complete, helping the addressee grasp the meaning expressed by the author. V. A. Artyomov, a well-known researcher of experimental phonology and speech psychology, thinks that prosody is the warp on which the intonation and the word are embroidered (Buraya 2009:187).

\section{Conclusion}

To sum up, it can be said that prosodic features are contextual factors which become meaningless out of context. They are utilized to give depth to utterances and reveal the underlying meanings. Prosody provides the necessary information for language comprehension and facilitates the comprehension process. It helps the addressee hear the text, process and simultaneously interpret it in his mental lexicon. Drama is characterized by a great variety of tones. Along with simple tones, complex tones are frequent in final as well as in non-final sense-groups. The range is wider than usual. The tempo varies greatly. Very often we come across logical and psychological rather than hesitation pauses which are used for stylistic considerations, i.e. for attaching certain colouring to speech and revealing the hidden shades of meaning. Prosody may somehow be exaggerated in the drama for the purpose of maintaining intelligibility in the process of speech continuity. Thus, prosodic information is, in fact, of vital importance.

\section{References:}

1. Crystal, D. (2008) A Dictionary of Linguistics and Phonetics. $6^{\text {th }}$ ed. Blackwell Publishing Ltd (C) 555 pp. Available at: <https://anekawarnapendidikan.files. wordpress.com/2014/04/a-dictionary-of-linguistics-and-phonetics-by-davidchristal.pdf> [Accessed December 2017]. 
2. Erekson, J.A. Prosody and Interpretation. Available at: $<$ http://scholarworks.wmich.edu/cgi/viewcontent.cgi?article=1008\&context= reading_horizons $>$ [Accessed January 2018].

3. Schopenhauer, A. On Style. Available at: <https://ebooks.adelaide.edu.au/s/schopenhauer/arthur/lit/chapter2.html $>$ [Accessed January 2018].

4. Buraya, Ye.A. (2014) Fonetika sovremennogo anglijskogo yazika. Teoreticheskij kurs: uchebnik dlya stud. uchrezhdenij vyssh. prof. obrazovaniya. / Ye.A. Buraya, I.E. Galochkina, T.I. Shevchenko. 4-e izd., ispr. i dop. M.: Izdatel'skij centr "Akademiya”, $288 \mathrm{~s}$.

\section{Sources of Data:}

1. Wilde, O. The Importance of Being Earnest. Available at: $<$ http://pinkmonkey.com/ dl/library1/earnest.pdf $>$ [Accessed January 2018].

2. Wilde, O. The Importance of Being Earnest. Act I. Available at: $<$ https://www.youtube.com/watch?v=dIwJLTFCuHE > [Accessed January 2018].

\section{Unnquinıpjuil ntepn untpunp utiquupuinıpjuid utig}

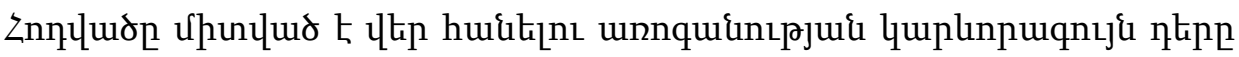

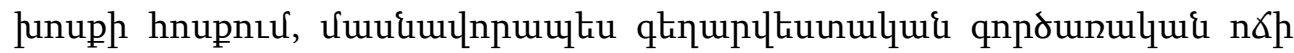

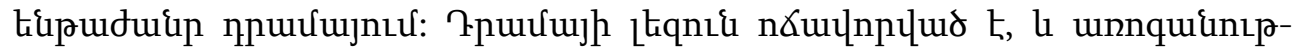

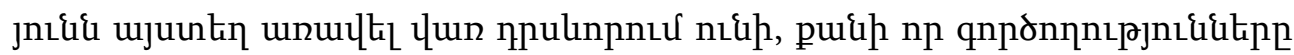

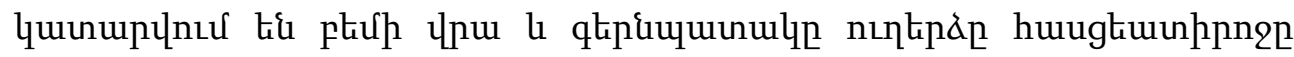

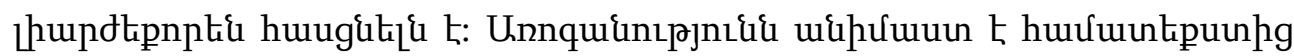

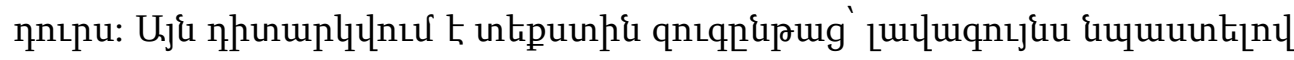

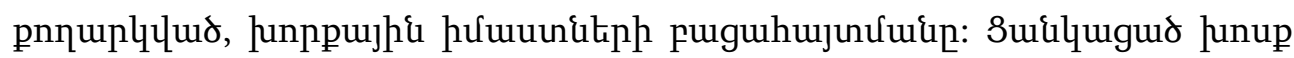

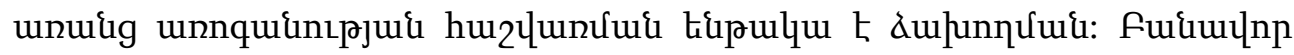

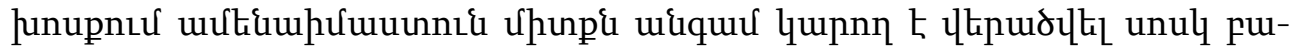

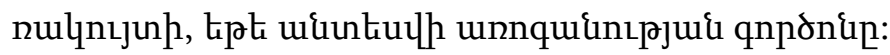

